ISSN 0103-9954

\title{
CLIMA E VEGETAÇÃO NATURAL DO ESTADO DO RIO GRANDE DO SUL SEGUNDO O DIAGRAMA CLIMÁTICO DE WALTER E LIETH
}

\section{CLIMATE AND NATURAL VEGETATION IN THE STATE OF RIO GRANDE DO SUL ACCORDING TO THE WALTER AND LIETH CLIMATIC DIAGRAM}

\author{
Galileo Adeli Buriol $^{1} \quad$ Valduino Estefanel $^{2} \quad$ Álvaro Chagas de Chagas ${ }^{3}$ Denise Eberhardt ${ }^{4}$ \\ RESUMO
}

\begin{abstract}
Relacionou-se a vegetação natural do estado do Rio Grande do Sul com as disponibilidades climáticas por meio do diagrama climático de Walter e Lieth (1967). Foram utilizadas as temperaturas médias mensais do ar e as médias dos totais mensais de chuva de 41 estações meteorológicas, no período de 1931-1960. Para cada estação meteorológica foi traçado um gráfico cartesiano no qual se colocaram, no eixo das abcisssas, os meses e, num dos eixos das ordenadas, a temperatura média mensal do ar, em ${ }^{\circ} \mathrm{C}$ e, no outro, a média dos totais mensais de chuva, em $\mathrm{mm}$, sendo a escala da representação da chuva o dobro daquela da temperatura. Constatou-se que, pelos diagramas climáticos, todo o território do Estado se enquadra no Zonobioma de clima úmido temperado quente e vegetação de florestas. Esses resultados indicam que o modelo fitoclimático de Walter e Lieth (1967) não é adequado para representar a distribuição geográfica da vegetação natural do Estado, pois esta não é formada somente por florestas, mas também por grandes áreas de vegetação do tipo campestre.
\end{abstract}

Palavras-chave: Precipitação pluviométrica; temperatura do ar; vegetação.

\section{ABSTRACT}

The natural vegetation in the State of Rio Grande do Sul was related to climatic availability through the climatic diagram of Walter and Lieth (1967). Values of mean monthly air temperature and rainfall from 41 meteorological stations during the period 1931-1960 were taken into account. For each meteorological station, a graph was plotted with months in the $\mathrm{x}$ axis and monthly air temperature and rainfall in the two $\mathrm{y}$ axis considering the y axis with rainfall two fold the y axis with air temperature. Results showed that Rio Grande do Sul as a whole fits in the zonobioma of warm humid temperate climate and forest vegetation. These results indicate the phytoclimate model of Walter and Lieth (1967) is not appropriate to represent the geographic distribution of the natural vegetation of the State, because this type of vegetation is not only that which covers the State that because it also parents praises.

Keywords: Rainfall; air temperature; vegetation.

\section{INTRODUÇÃO}

A disponibilidade climática de um local e/ou região é um dos mais importantes fatores determinantes da distribuição geográfica dos diferentes tipos de vegetação natural aí existentes. Pesquisadores têm buscado representar essa relação por meio de modelos matemáticos, denominados modelos fitoclimáticos. Dentre esses modelos, é bastante conhecido aquele de Walter e Lieth (1967). Esses autores se basearam no diagrama de Gaussen (1945), o qual considera que um mês é seco se o cociente da média dos totais mensais das precipitações pluviométricas, em $\mathrm{mm}$, pela temperatura média mensal, em ${ }^{\circ} \mathrm{C}$, é inferior 2 . A representação, num mesmo gráfico cartesiano, das temperaturas e precipitações pluviométricas mensais permite obter o diagrama ombrotérmico, o qual coloca em evidência os períodos secos e chuvosos.

Walter e Lieth (1967) sugeriram que os diferentes tipos de climas de uma região e/ou da Terra fossem caracterizados de forma simples e clara, utilizando somente os elementos climáticos mais importantes e, ainda, que as suas variações ao longo do ano fossem representadas de forma gráfica. Para isso,

1. Engenheiro agrônomo, Dr., Professor da Área de Ciências Naturais e Tecnológicas, Centro Universitário Franciscano, Rua dos Andradas, 1614, CEP 97010-032, Santa Maria (RS). Bolsista do CNPq. galileo@unifra.br

2. Engenheiro Agrônomo, MSc., Professor da Área de Ciências Naturais e Tecnológicas, Centro Universitário Franciscano, Rua dos Andradas, 1614, CEP 97010-032, Santa Maria (RS). valduino@unifra.br

3. Acadêmico do Curso de Geografia, Centro Universitário Franciscano, Rua dos Andradas, 1614, CEP 97010-032, Santa Maria (RS). Bolsista de Iniciação Científica. alv.ch@bol.com.br

4. Acadêmica do Curso de Engenharia Ambiental, Centro Universitário Franciscano, Rua dos Andradas, 1614, CEP 97010-032, Santa Maria (RS). Bolsista de Iniciação Científica.

Recebido para publicação em 17/01/2006 e aceito em 6/03/2007. 
consideraram adequado o diagrama climático proposto por Gaussen (1945). Por meio desse modelo, caracterizaram os diferentes climas da Terra utilizando as médias dos totais mensais de chuva e a temperatura do ar média mensal e publicaram um Atlas com mais de 8000 diagramas climáticos de todo o mundo. Consideraram que esses dois elementos climáticos, do ponto de vista da ecologia, são os mais importantes, e que sua representação gráfica permite a compreensão rápida e eficaz das variações climáticas ao longo do ano.

Walter et al. (1975) e Walter (1986), utilizando os diagramas climáticos realizados por Walter e Lieth (1967), mapearam os diferentes Zonobiomas terrestres, considerando que a constituição da vegetação natural e do solo depende das disponibilidades climáticas. Assim, em função das grandes zonas climáticas da Terra, classificaram nove Zonobiomas. Nos mapas apresentados por esses autores, no estado do Rio Grande do Sul, tem-se o Zonobioma V, clima temperado úmido. Isso corresponde a solos podzólicos amarelos e/ou vermelhos e à vegetação natural de florestas sempre verdes.

Nos trabalhos existentes que relacionam as disponibilidades climáticas e a vegetação natural do estado do Rio Grande do Sul não se têm informações de estudos em que tenham sido utilizadas as disponibilidades climáticas e o modelo fitoclimático de Walter e Lieth (1967). Entretanto, Burgos (1969; 1970) utilizou esse modelo fitoclimático para estudar a distribuição da vegetação natural da Província de Buenos Aires e da Região Nordeste da Argentina. O autor constatou que a relação entre as disponibilidades climáticas e o tipo de vegetação natural nessas regiões, sobretudo na Província de Buenos Aires, não coincide com aquela indicada nos Zonobiomas de Walter (1986). Considerando que as condições climáticas da Província de Buenos Aires e, especialmente, da Região Nordeste da Argentina são semelhantes às do estado do Rio Grande do Sul, seria importante que os diagramas climáticos segundo Walter e Lieth (1967) fossem realizados também com os dados climáticos das diferentes Regiões Climáticas do Estado e relacionados com a vegetação natural aí existente.

Tendo em vista o exposto, neste trabalho, buscou-se determinar a relação entre as disponibilidades climáticas e a vegetação natural do estado do Rio Grande do Sul por meio do diagrama climático de Walter e Lieth (1967).

\section{MATERIAL E MÉTODOS}

Utilizaram-se as temperaturas médias mensais do ar e as médias dos totais mensais de chuva de 41 estações meteorológicas do estado do Rio Grande do Sul, período 1931-1960, publicados em Instituto de Pesquisas Agronômicas (1989). Na Tabela 1, tem-se a relação das estações meteorológicas utilizadas e suas respectivas coordenadas geográficas.

Para cada estação meteorológica, foi traçado um gráfico cartesiano segundo a metodologia proposta por Gaussen (1945) e recomendada por Walter e Lieth (1967) o que consistiu num diagrama, sendo colocados os meses no eixo das abcissas e num dos eixos das ordenadas a temperatura média mensal, em ${ }^{\circ} \mathrm{C}$, e no outro eixo a média dos totais mensais de precipitação pluviométrica, em $\mathrm{mm}$, sendo a escala de representação da precipitação pluviométrica o dobro daquela da temperatura do ar. Por exemplo, $20 \mathrm{~mm}$ na escala da precipitação está na mesma altura que $10^{\circ} \mathrm{C}$ naquela da temperatura. Esses gráficos foram denominados por Walter e Lieth (1967) de diagramas ecológicos do clima.

Os diagramas climáticos permitiram enquadrar, para cada estação meteorológica, o Zonobioma da classificação de Walter (1986) e, ainda, caracterizar os climas homólogos do Estado.

\section{RESULTADOS E DISCUSSÃO}

Nas Figuras 1 a 4, tem-se a representação dos climogramas das estações meteorológicas das diferentes regiões climáticas do estado do Rio Grande do Sul, regiões essas definidas segundo Araújo (1930) e Machado (1950). Observa-se que, em todas as estações meteorológicas, a linha que representa as médias dos totais mensais de precipitação pluviométrica localiza-se acima daquela da temperatura média mensal do ar, fato que caracteriza condições de clima úmido. As temperaturas médias mensais do mês mais frio são superiores a $11,3^{\circ} \mathrm{C}$ e do mês mais quente são inferiores a $26,0^{\circ} \mathrm{C}$ o que caracteriza um clima temperado quente. Essas disponibilidades climáticas correspondem ao Zonobioma V da classificação de Walter (1986), característica de vegetação natural de florestas. 
TABELA 1: Coordenadas geográficas das estações meteorológicas utilizadas no trabalho.

TABLE 1: Geographic coordinates of the meteorological stations used in the study.

\begin{tabular}{lccc}
\hline Estação & Latitude Sul & Longitude Oeste & Altitude (m) \\
\hline Irai & $27^{\circ} 11^{\prime} 45$ & $53^{\circ} 14^{\prime} 01$ & 227 \\
Marcelino Ramos & $27^{\circ} 27^{\prime} 40$ & $51^{\circ} 54^{\prime} 2$ & 383 \\
Santa Rosa & $27^{\circ} 51^{\prime} 50$ & $54^{\circ} 25^{\prime} 59$ & 360 \\
Palmeira das Missões & $27^{\circ} 53^{\prime} 55$ & $53^{\circ} 26^{\prime} 45$ & 634 \\
Passo Fundo & $28^{\circ} 15^{\prime} 39$ & $52^{\circ} 24^{\prime} 33$ & 678 \\
Santo Ângelo & $28^{\circ} 18^{\prime} 14$ & $54^{\circ} 15^{\prime} 52$ & 289 \\
São Luiz Gonzaga & $28^{\circ} 23^{\prime} 53$ & $54^{\circ} 58^{\prime} 18$ & 254 \\
Lagoa Vermelha & $28^{\circ} 25^{\prime} 35$ & $51^{\circ} 35^{\prime} 51$ & 805 \\
Vacaria & $28^{\circ} 33^{\prime} 00$ & $50^{\circ} 42^{\prime} 21$ & 955 \\
São Borja & $28^{\circ} 39^{\prime} 44$ & $56^{\circ} 00^{\prime} 15$ & 96 \\
Cruz Alta & $28^{\circ} 38^{\prime} 21$ & $53^{\circ} 36^{\prime} 34$ & 473 \\
Bom Jesus & $28^{\circ} 40^{\prime} 10$ & $50^{\circ} 26^{\prime} 25$ & 1046 \\
Guaporé & $28^{\circ} 55^{\prime} 44$ & $51^{\circ} 54^{\prime} 45$ & 450 \\
Soledade & $29^{\circ} 03^{\prime} 14$ & $52^{\circ} 26^{\prime} 00$ & 720 \\
Itaqui & $29^{\circ} 07^{\prime} 10$ & $56^{\circ} 32^{\prime} 52$ & 53 \\
Bento Gonçalves & $29^{\circ} 10^{\prime} 00$ & $51^{\circ} 25^{\prime} 00$ & 619 \\
Caxias do Sul & $29^{\circ} 10^{\prime} 25$ & $51^{\circ} 12^{\prime} 21$ & 740 \\
Santiago & $29^{\circ} 11^{\prime} 00$ & $54^{\circ} 53^{\prime} 10$ & 426 \\
Júlio de Castilhos & $29^{\circ} 13^{\prime} 26$ & $53^{\circ} 40^{\prime} 45$ & 516 \\
São Francisco de Paula & $29^{\circ} 20^{\prime} 00$ & $50^{\circ} 31^{\prime} 21$ & 912 \\
Torres & $29^{\circ} 20^{\prime} 34$ & $49^{\circ} 43^{\prime} 39$ & 43 \\
\hline
\end{tabular}

Os menores valores médios dos totais mensais de precipitação pluviométrica ocorrem nas estações meteorológicas localizadas nas regiões climáticas do litoral sul e norte (Santa Vitória do Palmar, Jaguarão, Rio Grande, Pelotas, Tapes e Torres), Figura 1; Campanha (Santana do Livramento, Bagé, São Gabriel e Dom Pedrito), Figura 1; e Baixo Vale do Uruguai (Uruguaiana, Itaqui e São Borja), Figura 2. Valores intermediários das médias dos totais mensais de precipitação pluviométrica encontram-se nas regiões climáticas da Serra do Sudeste (Caçapava do Sul, Encruzilhada do Sul e Piratini), Figura 2; e Depressão Central (Alegrete, Santa Maria, Santa Cruz do Sul, Cachoeira do Sul, Porto Alegre, Taquara e Taquarí), Figuras 2 e 3. Os valores mais elevados das médias dos totais mensais de precipitação pluviométrica ocorrem nas regiões climáticas das Missões (Palmeira das Missões, Santiago, Santa Rosa, Santo Ângelo e São Luiz Gonzaga), Figura 3; Planalto (Julio de Castilhos, Cruz Alta, Passo Fundo, Soledade, Lagoa Vermelha, Vacaria e Bom Jesus), Figuras 3 e 4; Alto Vale do Uruguai (Iraí e Marcelino Ramos), Figura 4; e Serra do Nordeste (São Francisco de Paula, Caxias do Sul, Bento Gonçalves e Guaporé), Figura 4.

Os climogramas das estações meteorológicas das diferentes Regiões Climáticas do Estado são homólogos, indicando características pluviométricas semelhantes. Entretanto, apesar da distribuição ao longo dos 12 meses do ano ser semelhante para todas as regiões, na metade sul do Estado, Figura 1, as médias dos totais mensais são menores daquelas situadas na metade norte, Figura 4. Confrontando-se os climogramas das diferentes estações meteorológicas do Estado, Figuras 1 a 4, observa-se que são homólogos àqueles apresentados por Walter (1986) na caracterização do Zonobioma V. Porém, ao confrontar os climogramas das estações meteorológicas de cada local, com o mapa da distribuição geográfica da vegetação natural do Estado (Figura 5), constata-se que as formações da vegetação natural não coincidem com aquela apresentada por Walter (1986), que é de floresta pois, em grande parte do Estado, a vegetação natural é do tipo campestre campestre. As florestas estão localizadas, sobretudo, nas regiões do Alto Vale do Uruguai, Planalto, Serra do Nordeste e no rebordo da Serra Geral, entre a Depressão Central e Planalto e o Litoral Norte e Planalto.

As florestas e os campos são formações naturais, respectivamente, de clima úmido e de regiões relativamente secas (Marchiori, 2004). No entanto, no estado do Rio Grande do Sul, embora o clima seja do tipo úmido e temperado quente, típico de floretas, em torno de $46,3 \%$ da vegetação natural é constituída de 
formações campestres. Esse contraste entre áreas de matas e de formações campestres, dispostas lado a lado, em solos de mesmas características físicas, químicas e geomorfológicas, de mesma profundidade e com mesmas disponibilidades climáticas, foi muito bem descrito por estudiosos da vegetação natural do Estado como Klein (1975), Leite e Klein (1990), Lindman (1906), Maak (1948), Marchiori (2002; 2004) e Rambo (1956). Esses autores atribuem o contraste marcante entre matas e campos, em alternâncias repetidas dentro de uma mesma região homoclimática a fatores edáficos e, especialmente, à vigência de um clima anterior mais seco, semi-árido. A atual distribuição de campos e florestas seria conseqüência das sucessivas mudanças climáticas ocorridas na região. Até, aproximadamente, 10 mil anos atrás, o clima do Estado foi frio, de 10 mil a 8 mil até 4 mil a 3 mil anos atrás foi quente e seco, de 3 mil a 1 mil anos atrás o clima foi mais frio e úmido e, a partir de 1 mil anos atrás até o momento, mais quente e úmido. As análises de pólen encontrados no Estado confirmam a ocorrência de mudanças climáticas no passado (Markgraf, 1989; Behling et al., 2001). Assim, com a umidificação do clima ocorreu um avanço progressivo das espécies arbóreas a partir das margens dos rios e lagos. Entretanto haveria necessidade de mais tempo para as formações florestais ocuparem todo o território do Estado.

Marchiori (2004) afirma que "mesmo com a predominância atual de um clima de vegetação ombrófila, mais de $2 / 3$ da vegetação campestre do planalto gaúcho possui características xerófilas e/ou subxerófilas". Afirma ainda que "a explicação da coexistência e da alternância brusca entre florestas e campos no Estado, mais do que nas disponibilidades de clima e solo, deve ser buscada na biologia das plantas representativas dos respectivos biomas e em suas vinculações com o relevo". Segundo esse autor, as gramíneas e as plantas lenhosas, com exceção nos climas tropicais, são antagônicas quanto ao sistema radicular e consumo da água. As gramíneas possuem um sistema radicular adaptado a regiões secas e solos arenosos. As espécies lenhosas possuem um sistema radicular mais extenso e profundo do que as gramíneas, sendo mais eficientes na extração da água em solos rochosos onde a água se distribui de forma irregular. As gramíneas, quando existe umidade abundante no solo apresentam intensa atividade fotossintética e, mesmo a umidade diminuindo, continuam a transpirar continuamente até a parte aérea secar, permanecendo após em estado vegetativo somente as raízes e o cone vegetativo caulinar, protegidos pela massa seca da parte aérea sobre o solo. Com a reposição da umidade do solo, reiniciam o crescimento. Já as espécies lenhosas controlam de forma mais eficiente a perda de água por transpiração nos períodos de deficiência hídrica pelo fechamento dos estômatos. Entretanto, nos períodos de intensa deficiência, o controle estomático não é suficiente para minimizar o efeito da deficiência de umidade do solo, ocorrendo a queda das folhas e, a continuar a deficiência hídrica, podem chegar à morte. Essas deficiências, segundo Marchiori (2004), favorecem a interpretação da vegetação campestre no Estado como formação relitual. A expansão das florestas sobre as áreas campestres deve-se às condições de clima úmido e quente ocorrente no Holoceno, partindo de florestas sobreviventes do último período Glacial Pleistocênico e de áreas florestais situadas ao norte.

Em vista dos resultados aqui obtidos, constata-se que o modelo fitoclimático de Walter e Lieth (1967) não é adequado para explicar a distribuição geográfica da vegetação natural do estado do Rio Grande do Sul. Burgos $(1969,1970)$ já havia constatado esse problema ao utilizar o modelo para relacionar as condições climáticas com a vegetação natural da Província de Buenos Aires e da Região Nordeste, na Argentina. Este autor, além do modelo de Walter e Lieth (1967), utilizou em seus estudos, outros modelos fitoclimáticos conhecidos universalmente. Seria importante que também esses modelos fossem aplicados às condições climáticas do Rio Grande do Sul para confirmar sua validade na região. 

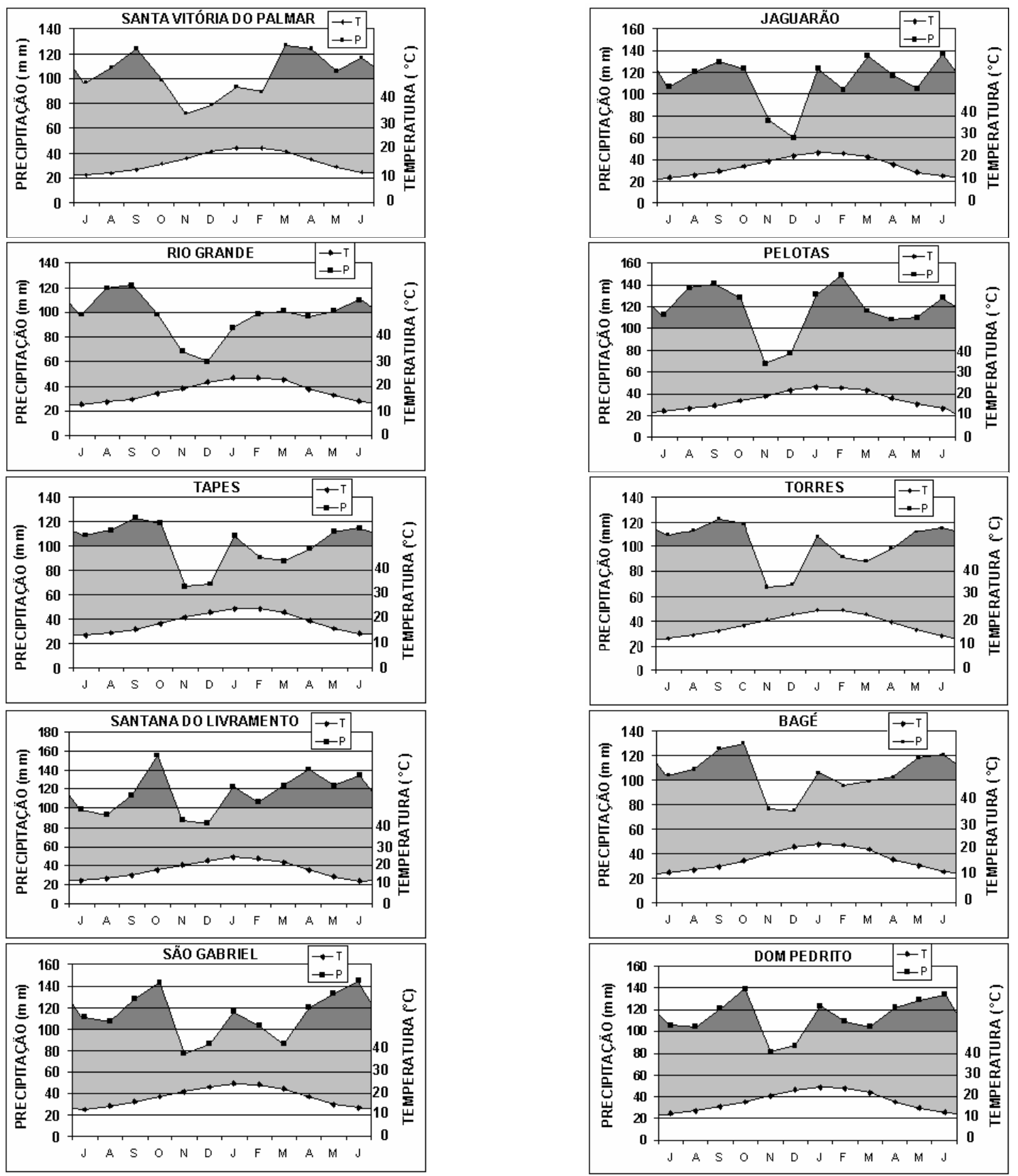

FIGURA 1: Diagramas Climáticos para as estações meteorológicas de Santa Vitória do Palmar, Jaguarão, Rio Grande, Pelotas, Tapes, Torres, Santana do Livramento, Bagé, Dom Pedrito e São Gabriel, segundo a metodologia de Gaussen (1945), proposta por Walter e Lieth (1967).

FIGURE 1: Climatic diagrams for meteorological stations of Santa Vitória do Palmar, Jaguarão, Rio Grande, Pelotas, Tapes, Torres, Santana do Livramento, Bagé, Dom Pedrito and São Gabriel, according to the metodology of Gaussen (1945) proposed by Walter and Lieth ( 1967). 

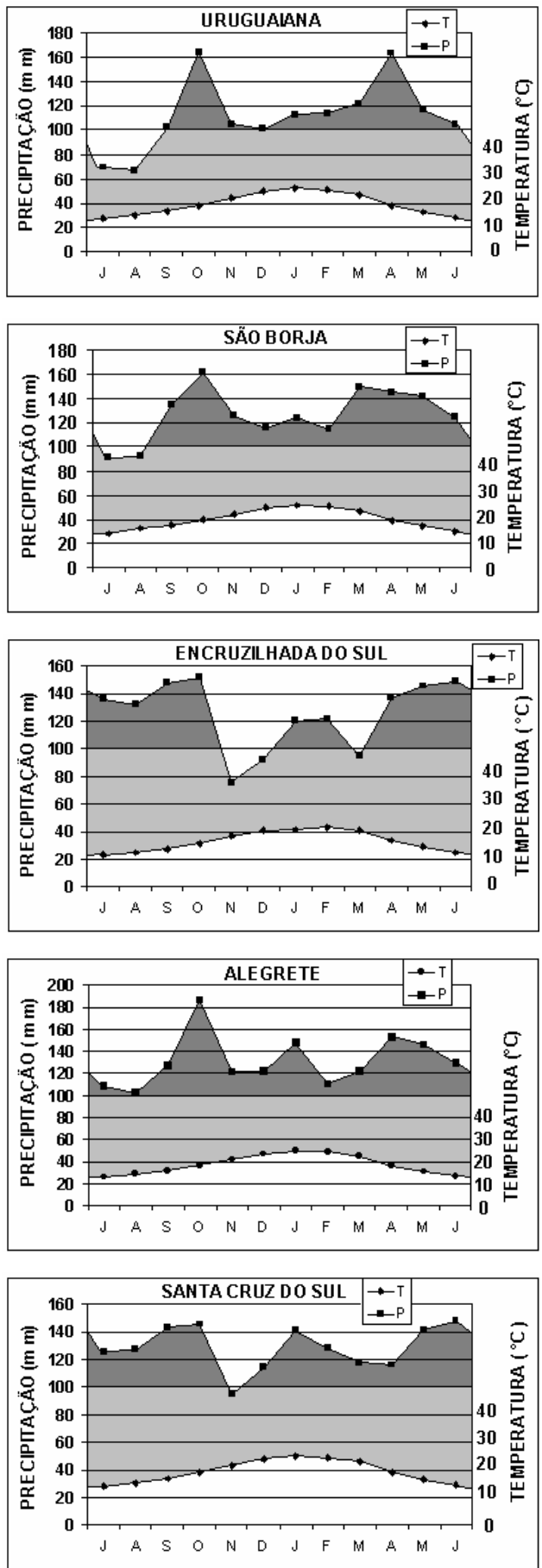
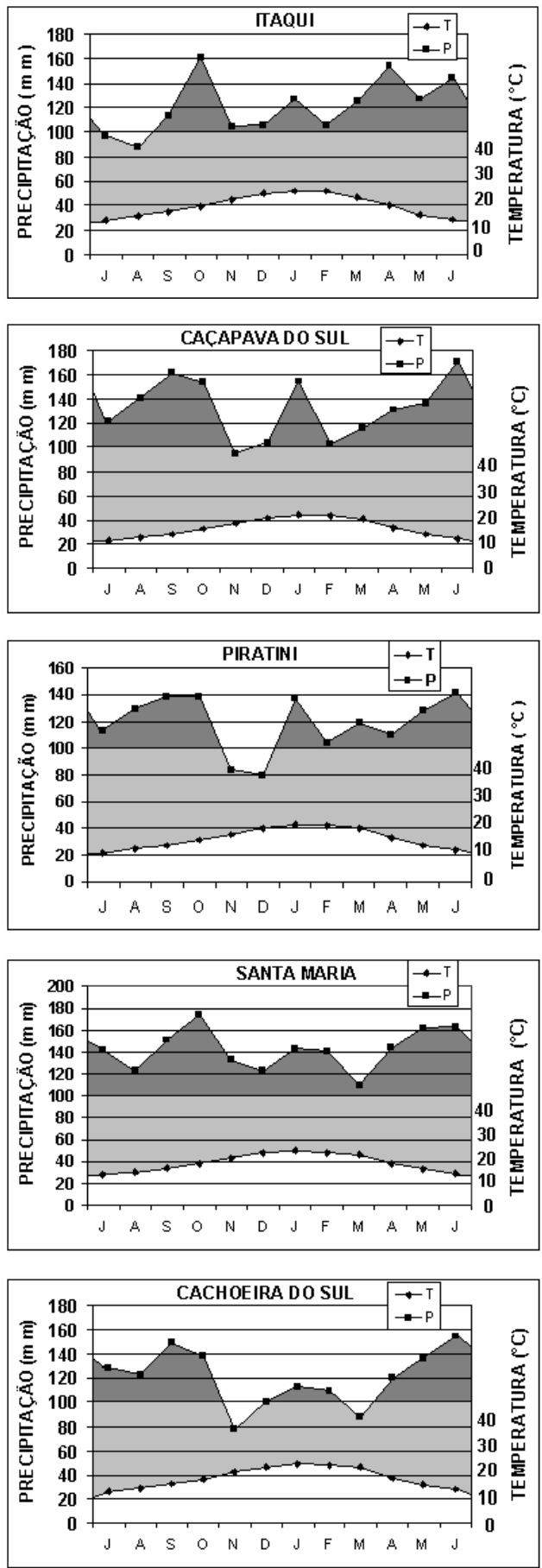

FIGURA 2: Diagramas Climáticos para as estações meteorológicas de Uruguaiana, Itaqui, São Borja, Caçapava do Sul, Encruzilhada do Sul, Piratini, Alegrete, Santa Maria, Santa Cruz do Sul e Cachoeira do Sul, segundo a metodologia de Gaussen (1945), proposta por Walter e Lieth (1967).

FIGURE 2: Climatic diagrams for meteorological stations of Uruguaiana, Itaqui, São Borja, Caçapava, Encruzilhada do Sul, Piratini, Alegrete, Santa Maria, Santa Cruz do Sul and Cachoeira do Sul, according to the metodology of Gaussen (1945) proposed by Walter and Lieth (1967). 

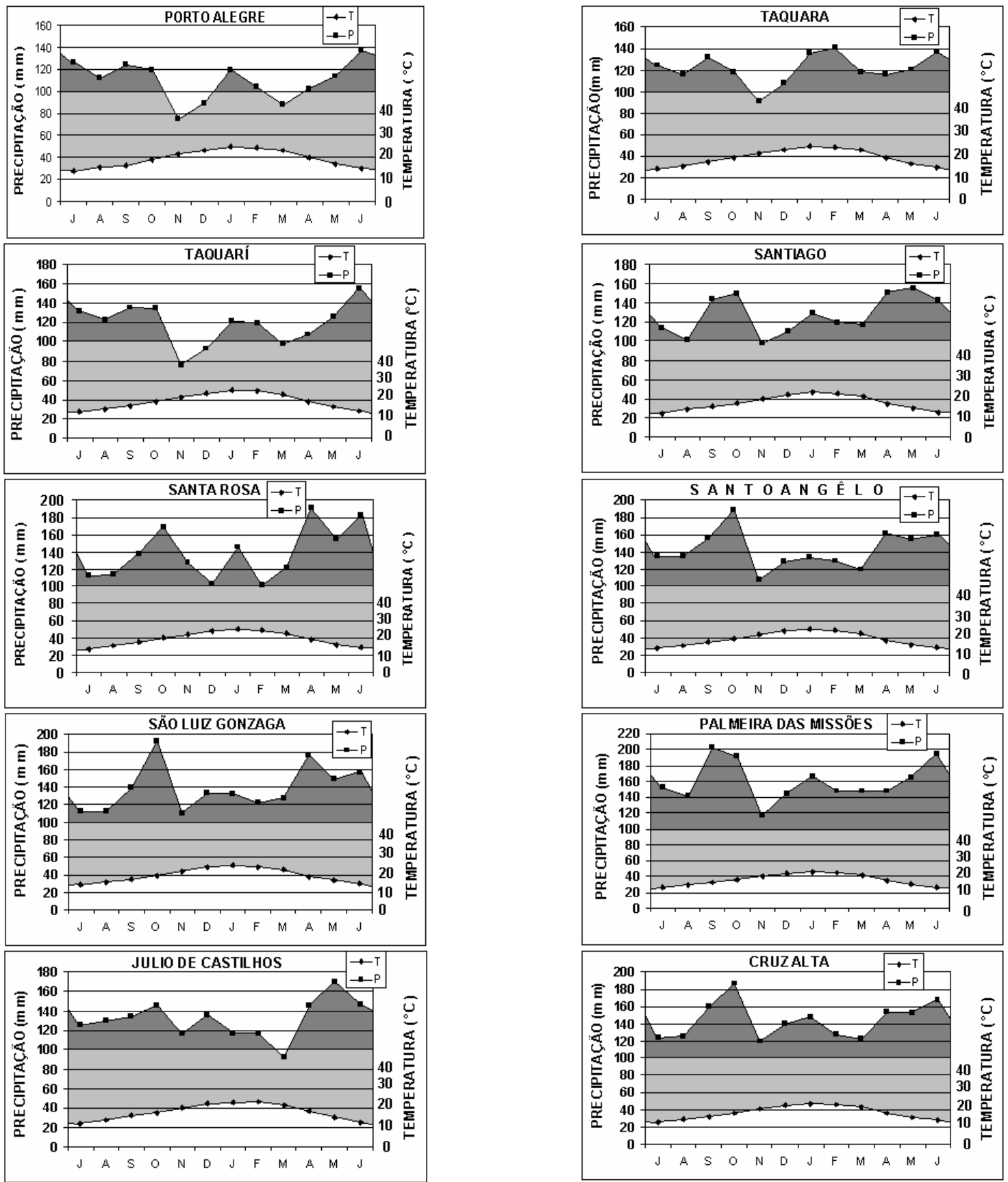

FIGURA 3: Diagramas Climáticos para as estações meteorológicas de Porto Alegre, Taquara, Taquari, Santiago, Santa Rosa, Santo Ângelo, São Luiz Gonzaga, Palmeira das Missões, Júlio de Castilhos e Cruz Alta, segundo a metodologia de Gaussen (1945), proposto por Walter e Lieth (1967).

FIGURE 3: Climatic diagrams for meteorological stations of Porto Alegre, Taquara, Taquarí, Santiago, Santa Rosa, Santo Ângelo, São Luiz Gonzaga, Palmeira das Missões, Julio de Castilhos and Cruz Alta, according to the metodology of Gaussen (1945) proposed by Walter and Lieth (1967). 

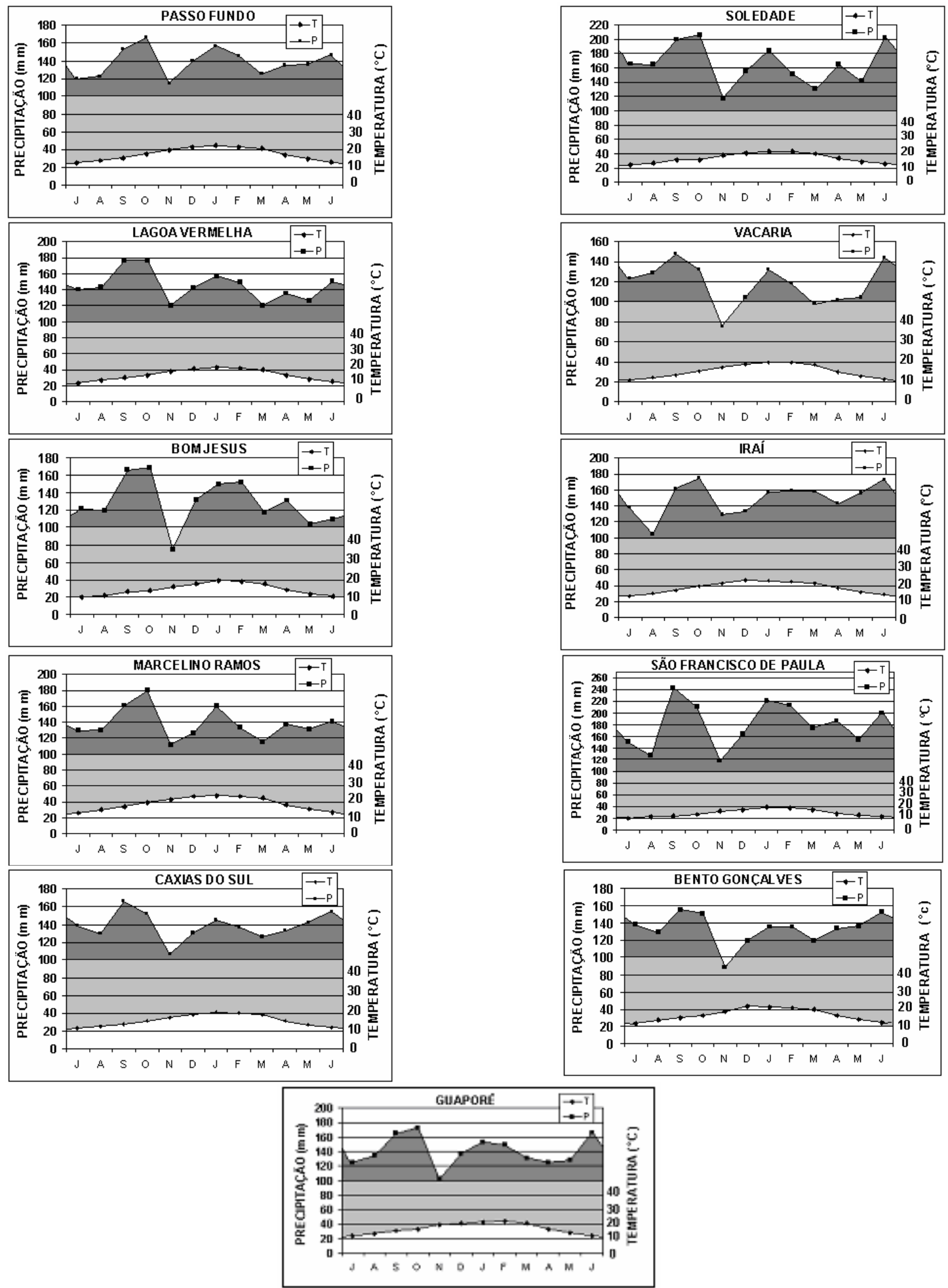

FIGURA 4: Diagramas climáticos para as estações climáticas de Passo Fundo, Soledade, Lagoa Vermelha, Vacaria, Bom Jesus, Irai, Marcelino Ramos, São Francisco de Paula, Caxias do Sul, Bento Gonçalves e Guaporé, segundo a metodologia de Gaussen (1945), proposta por Walter e Lieth (1967).

FIGURE 4: Climatic diagrams for meteorological stations of Passo Fundo, Soledade, Lagoa Vermelha, Vacaria, Bom Jesus, Iraí, Marcelino Ramos, São Francisco de Paula, Caxias do Sul, Bento Gonçalves and Guaporé, according to the metodology of Gaussen (1945) proposed by Walter and Lieth (1967). 


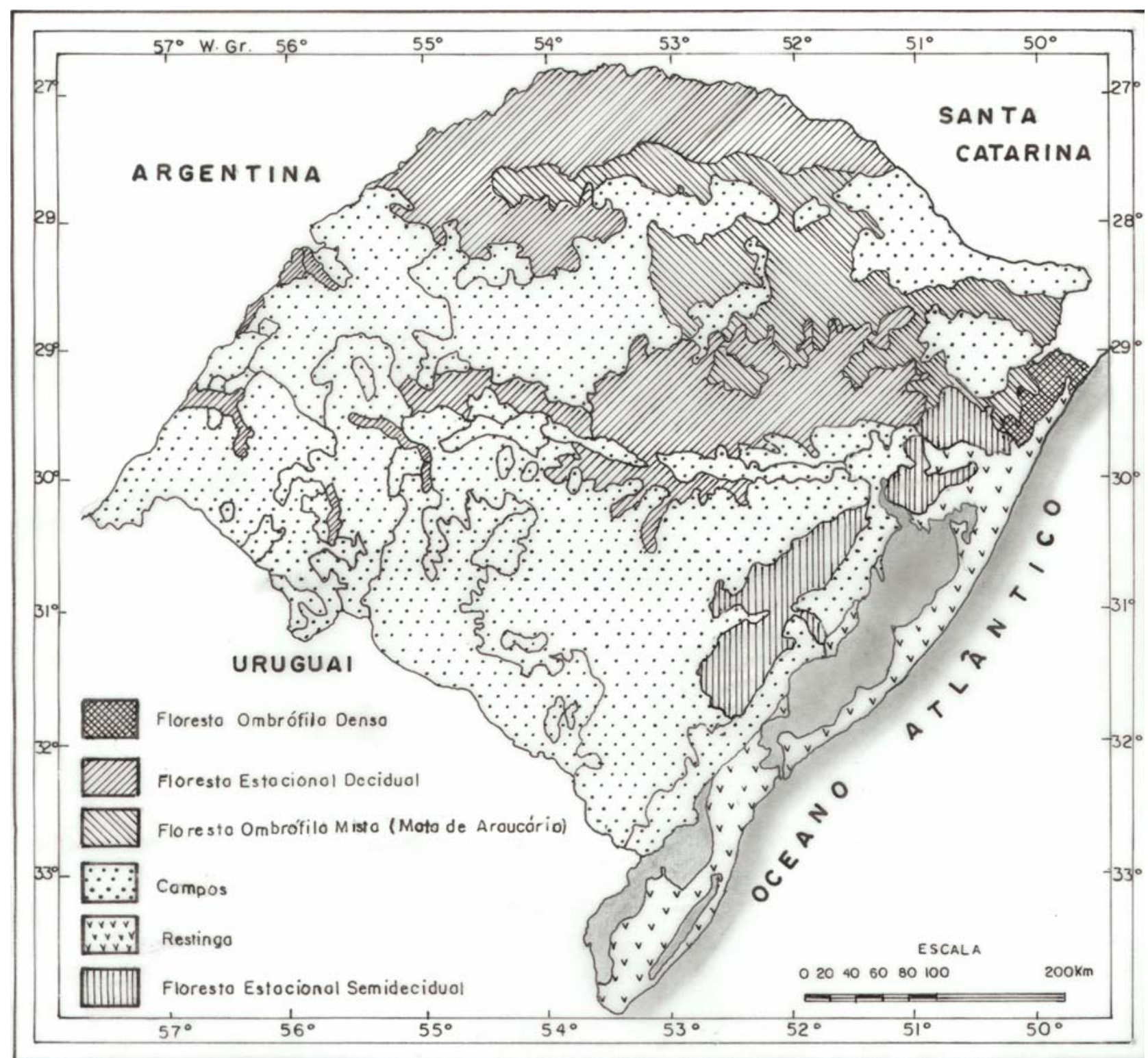

FIGURA 5: Mapa da vegetação potencial do estado do Rio Grande do Sul, Brasil (Adaptado de Hueck e Siebert, 1972; Klein, 1975; Teixeira et al., 1986 e Quadros e Pilar, 2002).

FIGURE 5: Potential vegetation map of Rio Grande do Sul, Brazil (adapted from Hueck and Siebert, 1972; Klein, 1975; Teixeira et al., 1986 and Quadros and Pilar, 2002).

\section{CONCLUSÕES}

As disponibilidades climáticas das diferentes Regiões Climáticas do estado do Rio Grande do Sul, segundo o climograma de Walter e Lieth (1967), enquadram o Estado no Zonobioma V de Walter (1986), características de um clima úmido e temperado quente e de vegetação natural de floresta. Entretanto, em torno de $50 \%$ da vegetação natural do Estado é do tipo campestre. Dessa forma, o modelo fitoclimático de Walter e Lieth (1967) não é adequado para explicar a distribuição geográfica da vegetação natural do estado do Rio Grande do Sul em função das disponibilidades climáticas.

Pelos diagramas climáticos realizados segundo a metodologia de Gaussen (1945), para as diferentes estações meteorológicas, constata-se que o clima do Estado é homólogo, diferindo apenas na intensidade dos totais mensais de chuva e das temperaturas médias mensais do ar, mas não na sua variação ao longo do ano. 


\section{REFERÊNCIAS BIBLIOGRÁFICAS}

ARAÚJO, L.C. Memória sobre o clima do Rio Grande do Sul. Rio de Janeiro: Serviço de Informações do Ministério da Agricultura, 1930. 101p.

BEHLING, H.; BANERMANN, S.G; NEVES, P.C. Halocene environmental changes in the São Francisco de Paula region, southrn Brazil. Journal of south American Earth Sciences, Columbia, v. 14, p. 631-639, 2001.

BURGOS, J.J. Clima de la Província de Buenos Aires en relacion con la vegetacion natural y el suelo. In: CABRERA, A.L. Flora de la Província de Buenos Aires. Buenos Aires: INTA, 1969. p.33-39.

BURGOS, J.J. El clima de la Region Nordeste de la Republica Argentina en relacion con la vegetacion natural y el suelo. Boletín de la Sociedade Argetina de Botânica, Buenos Aires, v. 11, p. 37-102, 1970.

GAUSSEN, H. Theories et classification des climats et microclimats. In: CONGRES INTERNATIONALE DE BOTANIQUE, 8., 1954, Paris. Compte-Rendu... Paris, 1954. Section 7 et 3, p. 125-130. 1954.

HUEC, K.; SEIBERT, P. Vegetationskarte von Sudamerika. Mapa de la vegetación de América del Sur. Stuttgart: Gustav Fischer, 1972.

INSTITUTO DE PESQUISAS AGRONÔMICAS. Atlas agroclimático do Estado do Rio Grande do Sul. Porto Alegre: Secretaria da Agricultura e Abastecimento, 1989. 296p. (v. 1).

KLEIN, R.M. Southern brazilian phytogeographic features and the probable influence of upper quaternary climatic changes in the floristic distribuition. Boletim Paranaense de Geociências, Curitiba, n. 33, p. 67-88, 1975.

LEITE,P.F.; KLEIN, R.M. Vegetação. In: Geografia do Brasil: Região Sul. Rio de Janeiro: Instituto Brasileiro de Geografia e Estatística, 1990. v. 2, p.113-150.

LINDMAN, C.A.M. A vegetação no Rio Grande (Brasil Austral). Porto Alegre: Livraria Universal de Echenique Irmãos, 1906. 356p.

MAAK, R. Notas preliminares sobre clima, solo e vegetação do Estado do Paraná. Arquivo Biológico Técnico, Curitiba, v. 3, p. 103-200, 1948.

MACHADO, F.P. Contribuição ao estudo do clima do Rio Grande do Sul. Rio de Janeiro : Instituto Brasileiro de Geografia, 1950. 91p.

MARCHIORI, J.N.C. Fitogeografia do Rio Grande do Sul: enfoque histórico e sistema de classificação. Porto Alegre: Edição EST, 2002. 118p.

MARCHIORI, J.N.C. Fitogeografia do Rio Grande do Sul: campos sulinos. Porto Alegre: Ed. EST, 2004. 110p.

MARKGRAF, V. Paleoclimates in Central and South America since 18000 BP based on pollen and lakelevel records. Quartenary Science reviews, London, v. 8, p. 1-24, 1989.

QUADROS, F.L.F.; PILLAR,V.de P. Transições florestas-campo no Rio Grande do Sul. Ciência e Ambiente, Santa Maria, v. 2, p. 109-118, 2002.

RAMBO, B. A fisionomia do Rio grande do Sul: ensaio de monografia natural. Porto Alegre: Selbach, 1956. 456p.

TEIXEIRA, M.B. et al. Vegetação. In: INSTITUTO BRASILEIRO DE GEOGRAFIA E ESTATÍSTICA. Levantamento de recursos naturais. Rio de Janeiro: IBGE, 1986. v. 33, p. 541-632.

WALTER, H.; LIETH, H. Klimadiagramamm-Weltatlos. Jena: Pusl. Gustav Fischer, 1967.

WALTER, H. Vegetação e zonas climáticas. São Paulo: Editora Pedagógica e Universitária, 1986. 325p.

WALTER, H. ; HANICKELL, E. ; MÜLLER-DOMBOIS, D. Klimadiagramm-Karten der einzelnen Kontinente und ökologische Klimagliederung de Erde. Stuttgart : Gustav Fischer, 1975. 36p. e 9 mapas. 